\title{
Synthesis of margarine fat from sesame oil and palm stearin by chemical interesterification
}

\author{
${ }^{1,{ }^{*}}$ Siswanti, ${ }^{2}$ Hastuti, P., ${ }^{2}$ Supriyanto and ${ }^{1}$ Anandito, R.B.K. \\ ${ }^{1}$ Department of Food Science and Technology, Universitas Sebelas Maret (UNS), Jl. Ir. Sutami $36 \mathrm{~A}$ \\ Kentingan Surakarta 57126, Central Java, Indonesia \\ ${ }^{2}$ Department of Food Science and Technology, Universitas Gadjah Mada (UGM), Indonesia
}

\section{Article history:}

Received: 7 December 2020

Received in revised form: 16

February 2021

Accepted: 27 June 2021

Available Online: 4 July 2021

\section{Keywords:}

Chemical interesterification, Margarine fat,

Palm stearin,

Sesame oil

DOI:

https://doi.org/10.26656/fr.2017.5(S2).015

\begin{abstract}
The production of margarine fat is not only intended to be free from Trans Fatty Acid (TFA) but is also expected to have a higher quality from a nutritional aspect. In this research, margarine fat from sesame oil (SO) and palm stearin (PS) by a chemical interesterification was synthesized. Chemical interesterification is one of the processes used to modify the physico-chemical characteristics of oils and fats. An attempt to chemical-restructure palm stearin and sesame oil to form margarine fat which is suitable for margarine was investigated using sodium methoxide as a catalyst. The effect ratio of $\mathrm{PS} / \mathrm{SO}$ in color, slip melting point, solid fat index, texture and triacylglycerols $\left(\mathrm{TAG}_{\mathrm{S}}\right)$ profile of margarine fat were studied in research. This research was conducted by three major stages; characterization of sesame oil and palm stearin, synthesis of margarine fat by physical blending and chemical interesterification, and characterization of margarine fat. This study used a Completely Randomized Design (CRD) with one factor, namely the ratio of sesame oil and palm stearin. Margarine fat produced with different variations of the raw material concentration (\% w/w SO:PS $=30: 70 ; 40: 60 ; 50: 50,60: 40$, and 70:30). Chemical interesterification caused: rearrangement of triacylglycerols, reduction of $\mathrm{S}_{3}$ and $\mathrm{U}_{3}$ and increase in $\mathrm{S}_{2} \mathrm{U}$ and $\mathrm{U}_{2} \mathrm{~S}$ type TAGs content of all blend, resulting in lowering of melting point, solid fat index and increase texture. Margarine fat in the $\%$ ratio of SO:PS = 60:40, has a similar characteristic (texture, slip melting point, solid fat index, and $\mathrm{TAG}_{\mathrm{S}}$ profiles) which margarine commercial, so has the potential to be developed in the manufacture margarine industry.
\end{abstract}

\section{Introduction}

Fats and oils are products that have a key role in improving the acceptability of foods. They have important nutrients in the human diet (Jalili et al., 2018). Margarine is a product that has a large consumption rate in the world, both eaten directly and used in the confectionery industry. The main constituent of margarine production is margarine fat. In the food industry, spreadable margarine fat has important favorable organoleptic and functional properties (Saghafi et al., 2018). The important properties of fats for the manufacture of margarine are related to their melting properties. To provide the high melting point margarine fat, it is often obtained by partial hydrogenation, which can give the by-product of the trans- form isomer. Trans fatty acid (TFA) has contributed to the risk of several diseases such as coronary heart disease by increasing the level of triacylglycerol and the ratio of low-density lipoprotein (LDL) to high-density lipoprotein (HDL) cholesterol in blood plasma (Ahmadi and Marangoni, 2009; Brouwer et al., 2013).

Brouwer et al. (2013) said that most research on edible fats and oils and regulatory policy have focused on reducing TFA level in diets. Chemical interesterification does not produce TFA nor changes unsaturation level (Naeli et al., 2017). Chemical interesterification is one of the main modification processed available to food manufacturers to tailor the physical and chemical properties of food lipids (Farmani et al., 2009). Interesterification can improve the physical properties of fats and oils. They cause fatty acid redistribution within and among TAG molecules, which can lead to substantial changes in lipid functionally (Akoh, 2017). The interesterified blends of palm stearin and soybean oil resulted in desirable characteristics suited for the production of all-purpose shortening, 
Iranian vanaspati, and stick and Baker's margarine (Naeli et al., 2017).

The production of margarine fat is not only intended to be free from trans-fatty acids but is also expected to have the higher quality from a nutritional aspect. This can be done by making margarine fat from a mixture of vegetable oil and palm oil stearin. Sesame oil is one of the vegetable oils that are known to have high potential and nutritional quality. Sesame (Sesanum indicum L.) is one of the agricultural commodities with great potential as a producer of vegetable oil needed in the food, cosmetics and pharmaceutical industries (Carvalho et al., 2012). This plant comes from Central Asia, to be precise in India, Afghanistan and Tajikistan. Sesame earned the nickname The Queen of Oil Seed Crops, which reflects that sesame seeds have high nutritional content and have a positive impact on consumers.

Sesame seeds can produce sesame oil more than 40\% (Borjian Borojeni et al., 2016). Sesame oil has many advantages. It is used as cooking oil, in shortening and margarine, as a soap fat, in pharmaceuticals and as a synergist for insecticides (Döker et al., 2010). Sesame oil is beneficial for health because it contains a higher amount of unsaturated fatty acids (MUFA) than saturated fatty acids (SFA). Unsaturated fatty acids in sesame oil are oleic (omega 9) 38.1-43.2\% and linoleic acid (omega 6) $(36.2-43.1 \%)$, while the saturated fatty acid content is very small, namely palmitic acid $(4.8-11.5 \%)$ and stearic acid (5.3-13.3\%) (Carvalho et al., 2012). Sesame oil also contains lignans, including sesamol, sesamin and sesamolin. These lignans are known to function as antioxidants that inhibit lipid peroxidation. Besides containing lignans and vitamin E, sesame oil also contains $\beta$-carotene which also has the potential as an antioxidant to protect other compounds from oxidation (Corso et al., 2010).

To produce plastic margarine fat, a stearin fraction is needed which can increase its melting point. Palm stearin is a natural solid fraction obtained by fractionation of palm oil (Naeli et al., 2017). Palm oil and palm oil products are excellent base ingredients for margarine formulations. Blending and/or interesterification with other oils are used to improve its melting characteristics (Noor Lida et al., 2007; Farajzadeh Alan et al., 2019). The amount of palm stearin added will affect the properties of the resulting margarine. The main aim of this work was to investigate the effect of chemical interesterification on the color, slip melting point, solif fat index, texture and triacylglycerols profile of sesame oil and palm stearin blend.

\section{Materials and methods}

2.1 Materials

The raw material used in the extractions was fresh white sesame seeds of Sambirejo 1 variety which were 100 days old. Sesame seeds harvested in the dry season, namely in May 2010 which were obtained from sesame farmers in Central Java, Indonesia. The palm stearin used was obtained from PT Smart TBK Surabaya, East Java. Sodium methoxide (dry powder) was purchased from Merck. All other chemicals were of analytical grade and purchased from Merck.

\subsection{Characterization of sesame oil and palm stearin}

Previously, the sesame oil and palm stearin were used for characterization including testing: free fatty acid content (AOAC Cd 8-53, 1996), peroxide value (AOAC Ca 5a-40, 1996), water content (AOAC, 2000), antioxidant activity (DPPH method), total phenolic content (Folin-Ciocalteu method), fatty acid composition (AOCS Ce 2-66, 1996), slip melting point (AOCS cc. $3.25,1997$ ), solid fat index (AOCS Cd 10-57, 1997) and color (lovibon method) Lovibond PFXi-995.

\subsection{Synthesis of margarine fat by physical blending}

In this study, the margarine fat was made from a mixture of sesame oil (SO) and palm stearin (PS). The sesame oil used is sesame oil from roasting sesame seeds at $180^{\circ} \mathrm{C}$ for 30 mins (Purnamayati, 2011). The mixture is prepared in the proportions of 30:70, 40:60, 50:50, 60:40 and 70:30 SO:PS (\%w/w). The physical blending process carried out refers to the method used by (da Silva et al., 2010) are as follows: sesame oil and palm stearin which have been determined the amount is heated at $60^{\circ}$ $\mathrm{C}$ to melt all the fat crystals and homogenized for 20 mins at a speed of $100 \mathrm{rpm}$. Furthermore, the margarine fat is stored at $40^{\circ} \mathrm{C}$ before testing.

\subsection{Synthesis of margarine fat by chemical interestification}

Interestification begins with drying the margarine fat material (fat blend) as much as $250 \mathrm{~g}$ with a rotary evaporator with a water bath temperature of $45^{\circ} \mathrm{C}$. Drying is carried out for 20 mins to remove water. Then the fat blend is transferred to another beaker glass and it is weighed again. Sodium methoxide catalyst in powder form is added to the fat blend as much as $0.5 \%(\mathrm{w} / \mathrm{w})$. The interesterification reaction was carried out at $70^{\circ} \mathrm{C}$ in a water bath with $80 \mathrm{rpm}$ stirring for 60 mins. The reaction can be identified by the formation of a blackish color due to the formation of a complex between sodium and glyceride. The reaction was ended with washing 
using aquadest $\left(80^{\circ} \mathrm{C}\right)$ as much as $5 \mathrm{~mL}$ of water to deactivate the catalyst (da Silva et al., 2010).

\subsection{Margarine fat characterization}

The resulting margarine fat is then carried out characterization, which includes testing: color (lovibon method), slip melting point (AOCS cc. 3.25, 1997), solid fat index, texture (Lloyd Texture Analyzer) and triacylglycerols profile. Triacylglycerols profile was analysed refers to Mayamol et al., (2009) with modification. The reversed-phase used model 510, equipped with Model 410 differential refraction, as a detector (Millipore Corporation, Milford, MA) on a Lichrospere C-18 column $(150 \mathrm{~mm} \times 4 \mathrm{~mm}, 5 \mu \mathrm{m}$; Darmstadt, Jerman) with acetone/acetonitrile ( $75: 25$ by vol) as the mobile phase at a flow rate of $0.7 \mathrm{~mL} / \mathrm{min}$, and a refractive index (RI) detector. The sample concentration was adjusted to $1000 \mu \mathrm{g}$ in $20 \mu \mathrm{L}$. Individual peaks were identified by comparing the retention time with that of reference TAG (Sigma Chemical Co.USA).

\subsection{Statistical analysis}

This study used a completely randomized design (CRD) with one factor, namely the ratio of sesame oil and palm stearin formula. Data obtained were analyzed using SPSS version 15 with the One Way Analysis of Variances (ANOVA) method. A significant difference result would be followed by a significant difference test using Duncan's Multiple Range Test (DMRT) at the 5\% significance level. The difference test on margarine fat from physical blending and chemical interesterification used the Independent Sample Test method (T-Test Method).

\section{Result and discussion}

\subsection{Characteristics of sesame seeds, sesame oil and palm} stearin

The sesame used in this study has initial characteristics including water content of $7.85 \%$, weight $2.79 \mathrm{~g} / 1000$ seeds and oil contents of $58.92 \%$. The general properties of sesame oil and palm stearin used in this study can be seen in Table 1 . The free fatty acid levels of sesame oil and palm stearin used in this study were still quite low, namely $1.40 \%$ and $0.55 \%$. Akoh (2017) said that free fatty acids can impair catalyst performance, and levels should be maintained as low as possible.

The peroxide values of the sesame oil and palm stearin used in this study were 1.90 and 1.39 meq $\mathrm{O}_{2} / \mathrm{kg}$ of oil. This value still qualifies as an ingredient for the interesterification process in the manufacture of margarine fat. Akoh (2017) stated that the maximum peroxide number for materials to be used in the chemical interesterification process is lower than 5 meq $\mathrm{O}_{2} / \mathrm{kg}$ of oil. The sesame oil and palm stearin used in this study have low water content namely $0.18 \%$ and $0.11 \%$. Palm stearin water content shows a value less than the maximum price required as commercial oil. Shahidi (2005) states that the maximum water content of crude palm stearin is $0.25 \%$. According to (Akoh, 2017), the optimal water content for interesterification ranges from $0.04 \%$ to $11 \%(\mathrm{w} / \mathrm{v})$. High water content may interfere catalyst's activity so that it reduces the quality and product yield.

Table 1. Characteristics of sesame oil and palm stearin

\begin{tabular}{lcc}
\hline \multicolumn{1}{c}{ Characteristics } & Sesame Oil & Palm Stearin \\
\hline Free fatty acid content $(\%)$ & 1.40 & 0.55 \\
Peroxide value $\left(\right.$ meq $\left.\mathrm{O}_{2} / \mathrm{kg}\right)$ & 1.90 & 1.39 \\
Water content $(\%)$ & 0.18 & 0.11 \\
Antioxidant activity $(\%)$ & 42.74 & 19.78 \\
Total phenolic content $(\mathrm{mg} \mathrm{GAE} / \mathrm{g})$ & $2.4 .10^{-3}$ & $2.4 .10^{-3}$ \\
Fatty acid & & \\
$\quad 14: 0$ & - & 1.19 \\
$16: 0$ & 9.73 & 54.54 \\
$18: 1$ & 39.95 & 34.55 \\
$18: 2$ & 50.29 & 9.65 \\
$\quad 18: 3$ & 0.03 & 0.02 \\
Slip Melting Point $\left({ }^{\circ} \mathrm{C}\right)$ & $12-16$ & $52-55$ \\
Solid Fat Index & & \\
$\quad 10^{\circ} \mathrm{C}$ & 11.17 & 31.54 \\
$\quad 21.1^{\circ} \mathrm{C}$ & 9.19 & 30.28 \\
$\quad 33.3^{\circ} \mathrm{C}$ & 4.33 & 24.24 \\
Color (Lovibon Method) & & \\
$\quad$ Red & 4.6 & 0.0 \\
$\quad$ Yellow & 5.5 & 0.3 \\
\hline
\end{tabular}

Based on the results of research it can be seen that sesame oil and the palm stearin used still meets the requirements and have great potential as an ingredient in the manufacture of margarine fat through a chemical interesterification process. In addition, the low SMP and SFI values in sesame oil and the high SMP and SFI of palm stearin indicate the need for the incorporation of these two materials to produce the desired margarine fat.

\subsection{Characteristics of margarine fat result of chemical interesterification}

\subsubsection{Color}

In the process of making margarine fat, it produces red and yellow colors with different intensities. The data on the color of margarine fat produced by both physical blending and chemical interesterification with various variations in the ratio of sesame oil and palm stearin can be seen in Table 2 and Table 3. 
Table 2. Color of sesame oil, palm stearin and physical blended margarine fat

\begin{tabular}{llc}
\hline \multirow{2}{*}{ Sample } & \multicolumn{2}{c}{ Color } \\
\cline { 2 - 3 } & Red & Yellow \\
\hline Sesame Oil & $4.6^{\mathrm{d}}$ & $5.5^{\mathrm{d}}$ \\
Palm Stearin & $0.0^{\mathrm{a}}$ & $0.3^{\mathrm{a}}$ \\
Blend 30:70 & $0.1^{\mathrm{a}}$ & $0.1^{\mathrm{a}}$ \\
Blend 40:60 & $0.1^{\mathrm{a}}$ & $1.0^{\mathrm{b}}$ \\
Blend 50:50 & $0.1^{\mathrm{a}}$ & $1.0^{\mathrm{b}}$ \\
Blend 60:40 & $0.2^{\mathrm{b}}$ & $1.3^{\mathrm{c}}$ \\
Blend 70:30 & $0.9^{\mathrm{c}}$ & $1.3^{\mathrm{c}}$ \\
\hline
\end{tabular}

Values with the same superscripts are not significantly different $(\mathrm{p}>0.05)$.

Table 3. Color of sesame oil, palm stearin and margarine fat from chemical interesterification margarine fat

\begin{tabular}{lcc}
\hline \multirow{2}{*}{ Sample } & \multicolumn{2}{c}{ Color } \\
\cline { 2 - 3 } & Red & Yellow \\
\hline Sesame Oil & $4.6^{\mathrm{c}}$ & $5.45^{\mathrm{e}}$ \\
Palm Stearin & $0.0^{\mathrm{a}}$ & $0.3^{\mathrm{b}}$ \\
Blend 30:70 & $0.15^{\mathrm{a}}$ & $0.2^{\mathrm{a}}$ \\
Blend 40:60 & $0.17^{\mathrm{a}}$ & $0.6^{\mathrm{b}}$ \\
Blend 50:50 & $0.2^{\mathrm{a}}$ & $1.0^{\mathrm{c}}$ \\
Blend 60:40 & $0.5^{\mathrm{b}}$ & $1.0^{\mathrm{c}}$ \\
Blend 70:30 & $0.5^{\mathrm{b}}$ & $1.3^{\mathrm{d}}$ \\
\hline
\end{tabular}

Values with the same superscripts are not significantly different $(p>0.05)$.

The greater the percentage of sesame oil used, the more likely it will produce margarine fat with a greater red and yellow color intensity, either produced by physical blending or by chemical interesterification. This is because the sesame oil used, which is obtained from the roasting process of sesame seeds at $180^{\circ} \mathrm{C}$ for 30 mins, has a fairly high red and yellow intensity, namely 4.6 and 5.45. Research Borjian Borojeni et al. (2016) showed that the $L^{*}$ value of sesame oil color significantly decreased while $a^{*}$ and $b^{*}$ values increased over roasting. This means that the roasting process caused an increase in the dark, red, and yellow units of oil color. This can be due to the browning reactions (such as caramelization and Maillard reaction), oxidation, phospholipids degradation, polymerization and other chemical changes occurring at the high temperature of the process.

The process of making margarine fat by chemical interesterification tends to produce a higher red color intensity when compared to margarine fat which is only made by physical blending. The difference test using the T-test method showed that the red color intensity of the margarine fat produced by chemical interesterification was higher and significantly different $(0.05 \%)$ level when compared to the margarine fat produced by physical blending in all formulations. This is because, in the chemical interesterification process, there is a further heating process that can cause a higher red color.

\subsubsection{Slip melting point (SMP)}

The SMP margarine fat by physical blending and chemical interesterification are presented in Table 4. The SMP margarine fat decreased with the addition of sesame oil both by physical blending and chemical interesterification. This is because the higher the sesame oil fraction, the more potential donors of unsaturated fatty acids, thus giving the opportunity to replace the saturated acyl with the unsaturated one. Naeli et al. (2017) said that the SMP of blend increased with the increase of palm ratio because of the increase in S3 type $\mathrm{TAG}_{\mathrm{S}}$ content.

Table 4. Slip Melting Point (SMP) fat margarine by physical blending and chemical interesterification

\begin{tabular}{ccc}
\hline \multirow{2}{*}{ Ratio SO:PS } & \multicolumn{2}{c}{ Slip Melting Point $\left({ }^{\circ} \mathrm{C}\right)$} \\
\cline { 2 - 3 } & Physical Blending Chemical Interesterification \\
\hline $30: 70$ & $51-53$ & $48-50$ \\
$40: 60$ & $48-50$ & $46-49$ \\
$50: 50$ & $46-49$ & $43-45$ \\
$60: 40$ & $41-44$ & $37-39$ \\
$70: 30$ & $32-35$ & $27-30$ \\
\hline
\end{tabular}

In general, the SMP of margarine fat decreased after interesterification. The difference test using the T-test method showed that chemically interesterified margarine fat made with the ratio formulation of sesame oil: palm stearin $=30: 70,60: 40$ and 70:30 $(\% \mathrm{w} / \mathrm{w})$ had lower SMP and significantly different from the physical blending process. da Silva et al. (2010) stated that interesterification reduced the melting point of all blends. This was related to the reduction of the sum of the amounts of SU TAGs after the interesterification, caused by the incorporation of unsaturated fatty acids of olive oil into palm stearin. The melting points before interesterification were dependent on PS, and on the positive interactions between PS and OO (p_0.05). After interesterification, the melting points were dependent only on PS, as a consequence of the random rearrangement, which increased the compatibility between the fats. In the chemical interesterification process, there is a change in the composition of fatty acids in the triglycerides. Changes in the composition of these fatty acids will result in changes in their melting properties. After interesterification, the high melting trisaturated TAG decrease, while the monosaturatedunsaturated TAGs content increase (Karabulut et al., 2004; Soares et al., 2012; Farajzadeh Alan et al., 2019). For margarine fat with the percentage of sesame oil: palm stearin $=60: 40$, the SMP obtained was close to the SMP for commercial margarine, namely $37-39^{\circ} \mathrm{C}$. 

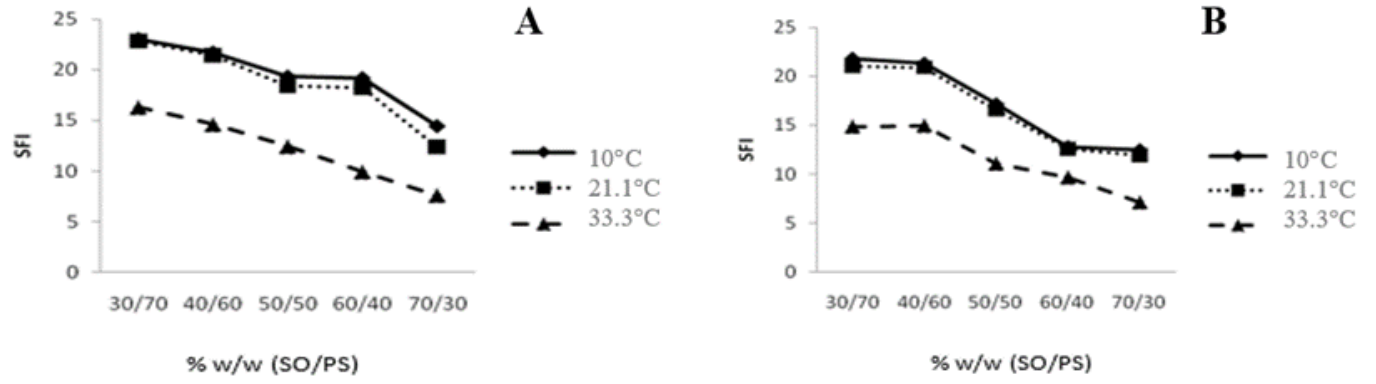

Figure 1. Solid Fat Index (SFI) at $10^{\circ} \mathrm{C}, 21.1^{\circ} \mathrm{C}$ and $33.3^{\circ} \mathrm{C}$ margarine fat by physical blending (a) and chemical interesterification (b)

\subsubsection{Solid fat index (SFI)}

Solid Fat Index (SFI) is the ratio between solid fat and liquid fat. It has a correlation with some functional properties such as consistency, spreadability, and sensorial acceptance (Augusto et al., 2012). The SFI margarine fat by physical blending and chemical interesterification is presented in Figure 1. In general, the SFI of margarine fat decreased with the higher ratio of the added sesame oil. The chemical interesterification process tends to reduce the SFI value in the resulting margarine fat. Margarine fat with percentage ratio of sesame oil: palm stearin $=50: 50$, and $60: 40(\% \mathrm{w} / \mathrm{w})$, by chemical interesterification showed a lower SFI value and significantly different than that by physical blending process using the T-test method. Solid Fat Index decrease after the chemical interesterification process is due to a decrease in $S_{3}$ and $S_{2} U$ types TAGs content which has high melting points more effective than physical blending (Karabulut et al., 2004; Soares et al., 2012; Farajzadeh Alan et al., 2019).

In the margarine fat with the percentage of sesame oil: palm stearin $=60: 40$ through a chemical interesterification process, the SFI value has almost the same character as the commercial margarine. Margarine fat 60:40, has SFI 12.80; 12.57; and 9.68 at 10;21.1; and $33.30^{\circ} \mathrm{C}$. This value was not significantly different from the commercial margarine SFI, namely $14.42 ; 14.23$; and 10.13 at a temperature of $0 ; 21.1$; and $33.30^{\circ} \mathrm{C}$.

The change in SFI indicates a change in the solid fraction of the fat or oil concerned. This is due to the exchange of acyls in the triglycerides in the mixture of sesame oil and palm stearin. Gunstone (2002) states that margarine has a Solid Fat Content value of $30-40 \%$ at $5^{\circ}$ $\mathrm{C}$ for good spreadability at refrigerator temperatures, SFC $10-20 \%$ at $10^{\circ} \mathrm{C}$ to get good resistance at room temperature, and $\mathrm{SFC}$ less than $3.5 \%$ at $35^{\circ} \mathrm{C}$ for complete melting in the mouth (at body temperature). The results of the research by (Akoh, 2017) commercial margarine and spreads have an SFI of $10^{\circ} \mathrm{C}$ ranging from 8.3-13.9 (for tub form) and 13.7-24 (for stick form), at $21.1^{\circ} \mathrm{C}$ ranges between 4.8-8.6 (for tub form) and 9.0-
13.0 (for stick form), at a temperature of $33.3^{\circ} \mathrm{C}$ ranges from 0.7-2.5 (for tub form) and 1, 7-3,2 (for stick form).

\subsubsection{Texture}

For most consumers, texture (plasticity) is an attribute of margarine which is a key factor affecting the appearance of the final product (Farajzadeh Alan et al., 2019). A good margarine texture is one that does not freeze at cold temperatures, remains plastic at room temperature and should melt completely at body temperature. Naeli et al. (2017) said that the soft tub margarine should be spreadable directly out of the refrigerator. The texture (plasticity) margarine fat by physical blending and chemical interesterification are presented in Figure 2. The texture of margarine fat increased with the higher percentage of palm stearin. Increasing solid fat content, the texture and consistency of margarine become tougher and stiffer. In texture testing, margarine fat to the ratio of sesame oil: palm stearin percentage was $60: 40$, resulting in a texture that was not significantly different from commercial margarine.

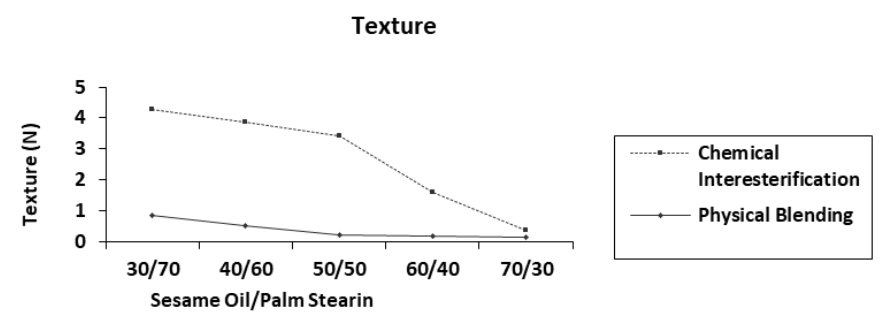

Figure 2. Texture of margarine fat by physical blending and chemical interesterification

The results also showed that margarine fat produced by physical blending processes had a lower texture or hardness value and was significantly different than margarine fat produced by chemical interesterification in the most sample. The texture level of margarine fat as a result of physical blending from various variations in the ratio of sesame oil and palm stearin is ranging from 0.14 to $0.86 \mathrm{~N}$. In margarine fat produced by chemical interesterification the texture or the resulting hardness is between $0.21-3.42 \mathrm{~N}$. 
These results indicate that chemical interesterification is better able to maintain the texture of the resulting margarine fat than if it only uses the usual physical blending process. Margoyungan (2004) states that blending is carried out with strong stirring so that the dispersion phases can be mixed. However, blending has many disadvantages due to differences in molecular size, the two types of oil may not be compatible with each other and can form a eutectic mixture. In addition, the results obtained are less stable in the long term because it is only a physical interaction of two or more types of oil.

On the other hand, by chemical interesterification, a more plastic texture of fat can be obtained. da Silva et al. (2010) stated that properties such as melting point, solid fat content, crystallization and rheology which are dependent on the TAGs profile, will be changed by interesterification. Interesterification is a method of modifying fats and oils that aims to increase and optimize their use in food products (Alan et al. 2019).

\subsubsection{Triacylglycerol (TAG) Profile}

Changes in SMP, SFI values, and the texture of margarine fats produced by chemical interesterification indicate changes in the solid fraction of the concerned fats or oils. This is due to the exchange of acyls in the triglycerides in the mixture of palm stearin and sesame oil. To determine changes in the composition of fatty acids in triglycerides before and after chemical interesterification, it is necessary to analyze the
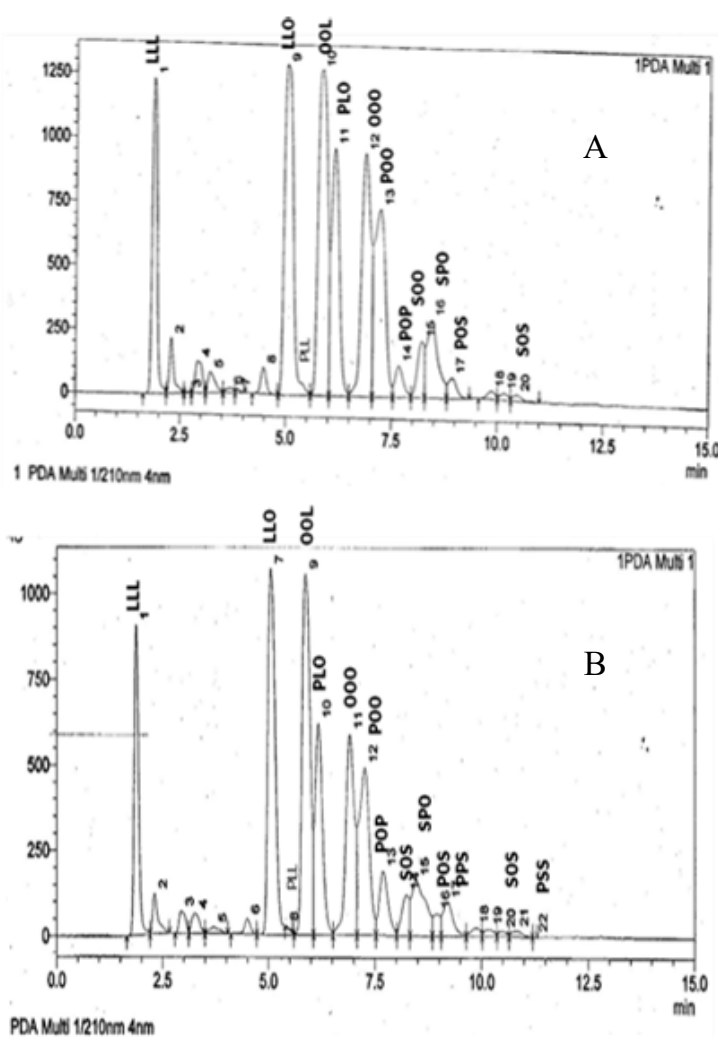

Figure 3. Chromatogram of TAGs distribution on sesame oil (a), fat margarine ratio (60:40) physical blending (b), fat margarine ratio (60:40) chemical interesterification (c), and palm stearin (d) triglyceride profile by means of high-performance liquid chromatography (HPLC). Chromatogram of TAGs distribution on sesame oil, fat margarine and palm stearin are presented in Figure 3.

Based on the research results, it can be seen that the chemical interesterification process tends to reduce the TAGs composition: LLL, LLO, OOL, OOO, PPP, PPS, and PSS types, as well as increase the TAGs of PLL and POP types. The TAGs profile of the chemically interesterified samples showed a better peak distribution than samples with the usual blending process. Some TAG shows an increase in concentration, some shows a decrease, and some new TAGs are formed. Chen et al. (2007) stated that the blending process carried out for most vegetable oils provides greater flexibility for products to be developed in large industries, mainly due to changes in specific functional properties and changes in nutritional content. However, the blending process does not provide chemical modifications to the TAGs component.

Margarine fat produced from the chemical interesterification process in the 60:40 formulation has lower in $\mathrm{U}_{3}$ and $\mathrm{S}_{3}$ type $\mathrm{TAG}_{\mathrm{S}}$ content than margarine fat produced from physical blending. $\mathrm{U}_{2} \mathrm{~S}$ and $\mathrm{S}_{2} \mathrm{U}$ type $\mathrm{TAG}_{\mathrm{S}}$ content on margarine fat produced from the chemical interesterification process in the formulation or 60:40, showed a larger area than the physical blended. Liu et al. (2010) stated that the lower $\mathrm{S}_{3}$ type $\mathrm{TAG}_{\mathrm{S}}$ content and the higher $\mathrm{S}_{2} \mathrm{U}$ type TAGs content, result in
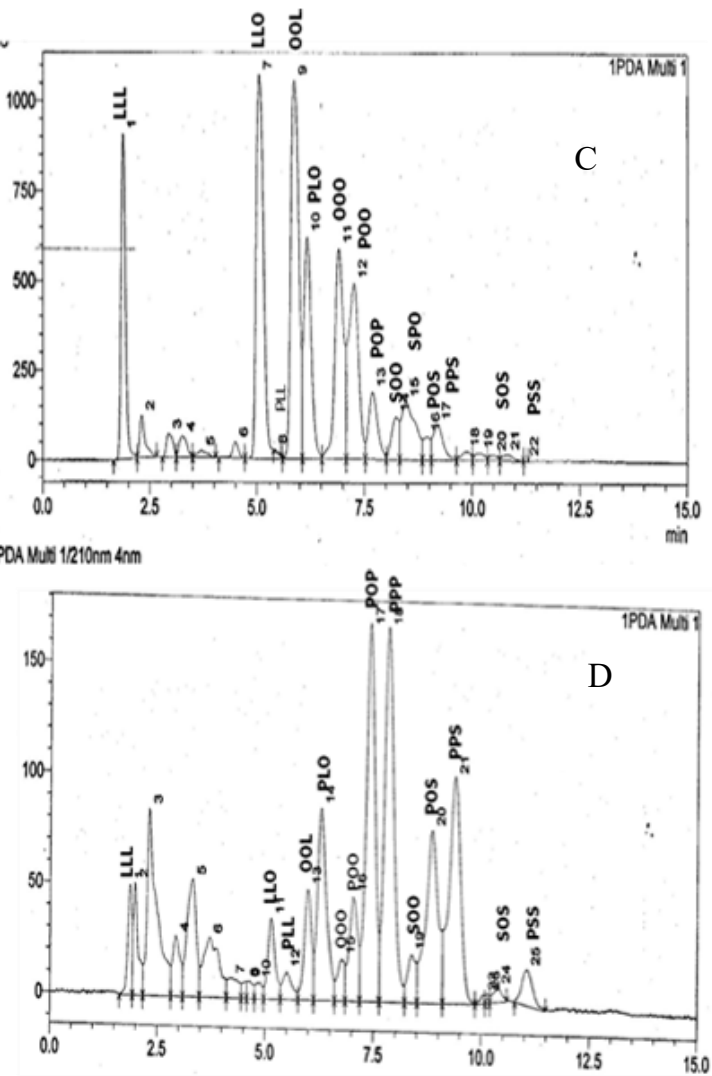
the lower formation of crystals at body temperature. In addition, the presence of POP type TAGs which is more than $45 \%$, will affect some crystallization properties because POP has low crystal formation and granule growth ability. Based Ribeiro et al. (2009) stated that the nature of fat in food is closely related to the composition of the constituent TAGs. $\mathrm{S}_{2} \mathrm{U}$ type TAGs content, with a melting point between $27^{\circ} \mathrm{C}$ and $42^{\circ} \mathrm{C}$ can affect the product structure. Meanwhile, the $\mathrm{U}_{2} \mathrm{~S}$ type TAGs content has a very important effect on the sensory and functional properties of the product at various temperatures.

The decrease in $\mathrm{U}_{3}$ and $\mathrm{S}_{3}$ and increase in $\mathrm{S}_{2} \mathrm{U}$ and $\mathrm{U}_{2} \mathrm{~S}$ type TAGs content caused by chemical interesterification processes can be associated with an increase in the function of processing technology. Changes in the TAGs profile can produce sensory characteristics, namely the texture of margarine fat that is close to commercial margarine so that this interesterification process can provide greater potential for application to food.

\section{Conclusion}

In the chemical interesterification of sesame oil and palm stearin, the ratio of sesame oil and palm stearin used as raw material plays a very important role in determining the color, slip melting point, solid fat index, texture, and the triacylglycerol profile of the resulting margarine fat. Margarine fat from chemical interesterification for 60 mins with $0.5 \%$ sodium methoxide catalyst, at a percentage ratio of sesame oil: palm stearin $=60: 40$, has characteristics (texture, slip melting point, solid fat index, and TAGs profile) similar to commercial margarine, so that it has the potential to be developed in the industrial field for the manufacture of margarine.

\section{References}

Ahmadi, L. and Marangoni, A.G. (2009). Functionality and physical properties of interesterified high oleic shortening structured with stearic acid. Food Chemistry, 117(4), 668-673. https://doi.org/10.1016/ j.foodchem.2009.04.072

Akoh, C.C. (Ed.) (2017). Chemical Interesterification of Food Lipids. In Food Lipids. BOca Raton, USA: CRC Press. https://doi.org/10.1201/978131515185413

Augusto, P.E.D., Soares, B.M.C., Chiu, M.C. and Gonçalves, L.A.G. (2012). Modelling the effect of temperature on the lipid solid fat content (SFC). Food Research International, 45(1), 132-135. https://doi.org/10.1016/j.foodres.2011.10.026
Borjian Borojeni, M., Goli, S.A.H. and Gharachourloo, M. (2016). Effect of roasted sesame oil on qualitative properties of frying oil during deep-fat frying. Journal of Agricultural Science and Technology, 18(6), 1531-1542.

Brouwer, I.A., Wanders, A.J. and Katan, M.B. (2013). Trans fatty acids and cardiovascular health: Research completed? European Journal of Clinical Nutrition, 67(5), 541-547. https://doi.org/10.1038/ejen.2013.43

Carvalho, R.H.R., Galvão, E.L., Barros, J.A.C., Conceição, M.M. and Sousa, E.M.B.D. (2012). Extraction, fatty acid profile and antioxidant activity of sesame extract: (Sesamum Indicum L.). Brazilian Journal of Chemical Engineering, 29(2), 409-420. https://doi.org/10.1590/S0104-66322012000200020

Chen, C.W., Chong, C.L., Ghazali, H.M. and Lai, O.M. (2007). Interpretation of triacylglycerol profiles of palm oil, palm kernel oil and their binary blends. Food Chemistry, 100(1), 178-191. https:// doi.org/10.1016/j.foodchem.2005.09.044

Corso, M.P., Fagundes-Klen, M.R., Silva, E.A., Cardozo Filho, L., Santos, J.N., Freitas, L.S. and Dariva, C. (2010). Extraction of sesame seed (Sesamun indicum L.) oil using compressed propane and supercritical carbon dioxide. Journal of Supercritical Fluids, 52 (1), 56-61. https://doi.org/10.1016/ j.supflu.2009.11.012

da Silva, R.C., Soares, D.F., Lourenço, M.B., Soares, F.A.S.M., da Silva, K.G., Gonçalves, M.I.A. and Gioielli, L.A. (2010). Structured lipids obtained by chemical interesterification of olive oil and palm stearin. LWT - Food Science and Technology, 43(5), 752-758. https://doi.org/10.1016/j.lwt.2009.12.010

Döker, O., Salgin, U., Yildiz, N., Aydoğmuş, M. and Çalimli, A. (2010). Extraction of sesame seed oil using supercritical $\mathrm{CO} 2$ and mathematical modeling. Journal of Food Engineering, 97(3), 360-366. https://doi.org/10.1016/j.jfoodeng.2009.10.030

Farajzadeh Alan, D., Naeli, M.H., Naderi, M., Jafari, S.M. and Tavakoli, H.R. (2019). Production of Trans -free fats by chemical interesterified blends of palm stearin and sunflower oil. Food Science and Nutrition, 7(11), 3722-3730. https://doi.org/10.1002/ fsn3.1231

Farmani, J., Safari, M. and Hamedi, M. (2009). Transfree fats through interesterification of canola oil/ palm olein or fully hydrogenated soybean oil blends. European Journal of Lipid Science and Technology, 111(12), 1212-1220. https://doi.org/10.1002/ ejlt.200900092

Jalili, F., Jafari, S.M., Emam-Djomeh, Z., Malekjani, N. and Farzaneh, V. (2018). Optimization of Ultrasound 
-Assisted Extraction of Oil from Canola Seeds with the Use of Response Surface Methodology. Food Analytical Methods, 11(2), 598-612. https:// doi.org/10.1007/s12161-017-1030-z

Karabulut, I., Turan, S. and Ergin, G. (2004). Effects of chemical interesterification on solid fat content and slip melting point of fat/oil blends. European Food Research and Technology, 218(3), 224-229. https:// doi.org/10.1007/s00217-003-0847-4

Liu, Y., Meng, Z., Zhang, F., Shan, L. and Wang, X. (2010). Influence of lipid composition, crystallization behavior and microstructure on hardness of palm oil-based margarine. European Food Research and Technology, 230(5), 759-767. https://doi.org/10.1007/s00217-010-1217-7

Mayamol, P.N., Balachandran, C., Samuel, T., Sundaresan, A. and Arumughan, C. (2009). Zero trans shortening using rice bran oil, palm oil and palm stearin through interesterification at pilot scale. International Journal of Food Science and Technology, 44(1), 18-28. https://doi.org/10.1111/ j.1365-2621.2008.01627.x

Naeli, M.H., Farmani, J. and Zargaraan, A. (2017). Rheological and Physicochemical Modification of trans-Free Blends of Palm Stearin and Soybean Oil by Chemical Interesterification. Journal of Food Process Engineering, 40(2), e12409. https:// doi.org/10.1111/jfpe. 12409

Noor Lida, H.M.D., Kalyana, S. and Nor Aini, I. (2007). Effect of chemical interesterification on triacylglycerol and solid fat contents of palm stearin, sunflower oil and palm kernel olein blends. European Journal of Lipid Science and Technology, 109(2), 147-156. https://doi.org/10.1002/ ejlt.200600198

Purnamayati, L. (2011). Optimization of Sesame Seeds (Sesamum Indicum L.) Roasting to the Changes of Bioactive Compounds of Sesame Oil and It's Application to Synthesis of Margarine Fats. Yogyakarta, Indonesia: Universitas Gadjah Mada. Thesis.

Ribeiro, A.P.B., Basso, R.C., Grimaldi, R., Gioielli, L.A., dos Santos, A.O., Cardoso, L.P. and Guaraldo Gonçalves, L.A. (2009). Influence of chemical interesterification on thermal behavior, microstructure, polymorphism and crystallization properties of canola oil and fully hydrogenated cottonseed oil blends. Food Research International, 42(8), 1153-1162. https://doi.org/10.1016/ j.foodres.2009.05.016

Saghafi, Z., Naeli, M.H., Tabibiazar, M. and Zargaraan, A. (2018). Zero-Trans Cake Shortening: Formulation and Characterization of Physicochemical,
Rheological, and Textural Properties. Journal of the American Oil Chemists' Society, 95(2), 171-183. https://doi.org/10.1002/aocs.12033

Shahidi, F. (Ed.) (2005). Bailey's Industrial Oil and Fat Oil and Fat. United Kingdom: Wiley Online Library https://doi.org/10.1002/047167849X

Soares, F.A.S.D.M., Da Silva, R.C., Hazzan, M., Capacla, I.R., Viccola, E.R., Maruyama, J.M. and Gioielli, L.A. (2012). Chemical interesterification of blends of palm stearin, coconut oil, and canola oil: Physicochemical properties. Journal of Agricultural and Food Chemistry, 60(6), 1461-1469. https:// doi.org/10.1021/jf204111t 